\section{AB0362 ANALYSIS OF INSULIN RESISTANCE IN A RHEUMATOID ARTHRITIS INCEPTION COHORT: CASE-CONTROL STUDY}

S. Manrique-Arija ${ }^{1}$, N. Mena-Vázquez ${ }^{1}$, I. Ureña ${ }^{1}$, S. Abad $^{2}$ M. Rojas-Gimenez ${ }^{1}$, L. Ginel ${ }^{2}$, L. Cano-Garcia ${ }^{1}$, C. Fuego ${ }^{1}$, C. Domic ${ }^{1}$, M.C. Ordoñez-Cañizares ${ }^{1}$, F.G. Jimenez-Nuñez ${ }^{1}$, G. Diaz-Cordoves ${ }^{1}$,

A. Belmonte ${ }^{1}$, V. Coret ${ }^{1}$, M.V. Irigoyen ${ }^{1}$, A. Fernandez-Nebro ${ }^{1} .{ }^{1}$ Department of Reumatology at the University Regional Hospital of Malaga (HRUM). Institute for Biomedical Research in Málaga (IBIMA). Malaga University; ${ }^{2}$ Ciudad Jardín (Guadalmedina) Health center. Hospital Regional de Málaga., Málaga, Spain

Objectives: To describe insulin resistance (IR) in patients with rheumatoid arthritis (RA) and compare it with healthy controls and to analyze the association between the accumulated inflammatory burden in patients with RA and IR.

Methods: Design: Observational case-control study. Population: consecutive RA-patients (ACR/EULAR 2010 criteria), >16 years, selected from a prospective inception cohort (diagnosis of RA between 2007 and 2011). Patients with Diabetes Mellitus (according to ADA 2010 criteria) were excluded. Controls: sex- age and BMI -matched controls were collected from a health center in our hospital area. Protocol: Cases and controls were evaluated by a rheumatologist. Clinical data of disease activity (RA patients), analytical values and oral glucose tolerance test (OGTT) were determined. All participants signed informed consent. Main outcome: IR measured by the homeostasis model for insulin resistance (HOMA-IR) $\left(\mathrm{IR}>2.29 \mu \mathrm{U}{ }^{*} \mathrm{mmol} / \mathrm{ml}\right)$. Secondary outcome: IR measured by quantitative insulin sensitivity check index (QUICKI) $(<0.337 \mu \mathrm{U}$ * $\mathrm{mmol} / \mathrm{ml})$ and by the homeostatic model assessment of $\beta$-cell function (HOMA $\beta$ ). Variables: Demographic, clinical-analytical variables, Disease Activity Score of 28 joints (DAS28-ESR), Health Assessment Questionnaire (HAQ), BMI (according to OMS classification) and glucose and insulin before and after OGTT values. Statistical analysis: Descriptive and paired T-test or Chi-square test followed by binary logistic regression in RA patients (Dependent variable: Insulin Resistance).

Results: Sixty-two subjects were studied, 8 of them were excluded after OGTT (4 diabetic patients and their respective controls). Finally, 54 subjects were included; 27 RA and 27 healthy controls. The mean age of patients with RA was 52.2 (12.1) years. Most of them were women (88.9\%), with seropositive (FR $81.5 \%$ and ACPA $74.1 \%$ ) and erosive (63\%) RA. The mean duration of the disease was 85.6 months (27.1) and mean DAS 28 index since the onset of the disease of $2.98(0.9)$.

Differences between clinical characteristics and in relation to IR between cases and controls are shown in Table 1. No significant differences in the proportion of subjects with IR in cases and controls were observed. $33.3 \%$ of patients with RA had IR. In multivariate analysis, the only independent variable associated with IR in RA patients was disease activity score (DAS28) $(\mathrm{OR}[95 \% \mathrm{Cl}]=3.6[1.0-12.9]$, $\mathrm{p}=0.045$ ).

Table 1

\begin{tabular}{|c|c|c|c|}
\hline VARIABLE & CASES $n=27$ & CONTROLS n=27 & $\begin{array}{c}\text { P - } \\
\text { VALUE }\end{array}$ \\
\hline Age, years; m ean $( \pm S D)$ & $52.2(12.0)$ & $52.3(12.3)$ & 0.979 \\
\hline Sex, women; $\mathbf{n}(\%)$ & $24(88.9)$ & $24(88.9)$ & 1 \\
\hline \multicolumn{4}{|l|}{ Comorbidities } \\
\hline $\mathrm{BMI}>\mathbf{3 0}$ (obesity) $\mathrm{n}(\%)$ & $5(18.5)$ & $4(14.8)$ & 0.715 \\
\hline BMI, mean $( \pm$ SD) & $26.7(4.6)$ & $26.3(5.4)$ & 0.776 \\
\hline W aist perimeter $(\mathrm{cm})$, mean $( \pm$ SD $)$ & $88.7(13.2)$ & $89.1(14.4)$ & 0.891 \\
\hline Hip perim eter $(\mathrm{cm})$, mean $( \pm$ SD) & $103.9(9.5)$ & $106.8(15.8)$ & 0.395 \\
\hline Dyslipemia, $n(\%)$ & $5(18.5)$ & $7(25.9)$ & 0.513 \\
\hline Hyp erten sion, $\mathbf{n}(\%)$ & $3(11.1)$ & $6(22.2)$ & 0.273 \\
\hline \multicolumn{4}{|l|}{ Insulin Resistance Indexes } \\
\hline HOMA-IR $>2,25, n(\%)$ & $9(33.3)$ & $7(25.9)$ & 0.551 \\
\hline HOMA-IR, mean $( \pm S D)$ & $1.9(10)$ & $1.7(1.1)$ & 0.514 \\
\hline HOMA- $\beta$, mean $( \pm$ SD) & $41.03(22.3)$ & $37.7(25.26)$ & 0.630 \\
\hline QUICKI, mean $( \pm$ SD) & $0.35(0.0)$ & $0.36(0.0)$ & 0.255 \\
\hline
\end{tabular}

Conclusions: The only predictor of IR in RA patients was the inflammatory activity measured by DAS28. We did not find a higher IR in RA patients than in healthy controls, it could be because the patients were well treated and the inflammatory activity was controlled in the most of them.

Disclosure of Interest: None declared

DOI: 10.1136/annrheumdis-2017-eular.6469

\section{AB0363 RESULTS OF SCREENING FOR VIRAL HEPATITIS IN RA PATIENTS TREATED WITH BIOLOGICS: HUR-BIO REAL LIFE RESULTS}

A. Sari, B. Armagan, A. Erden, L. Kilic, A. Akdogan, S. Apras Bilgen, I. Ertenli, U. Kalyoncu, S. Kiraz. Rheumatology, Hacettepe University School of Medicine, Ankara, Turkey

Background: Turkish Society of Rheumatology (TSR) proposed a guideline of recommendations for viral hepatitis screening before biological therapy in $2015 .{ }^{1}$
Objectives: The aim of this study was to assess results of viral hepatitis serological tests performed before biologics in RA patients.

Methods: HUR-BIO (Hacettepe University Rheumatology Biologic Registry) is a prospective,single center database of biological treatments including 1229 RA patients by August 2016. Results of serological tests for HBV of 468 RA patients were evaluated. The guideline includes 5 groups according to hepatitis $B$ virus (HBV) serology; group 1 -HBV seronegative [ $\mathrm{HbsAg}(-)$, anti $\mathrm{HbS}(-)$, anti-Hbc total (-)], group 2-vaccinated [HBsAg (-), anti-HBs (+), anti-HBc total (-)], group 3-previous HBV infection [HBsAg (-), anti-HBs (-), anti-HBc total (+)], group 4Chronic HBV infection [HBsAg (+), anti-HBs (-), anti-HBc total (+)], group 5secondary immunity [HBsAg (-), anti-HBs (+), anti-HBc total (+)]. Patients were also classified according to risk for HBV reactivation as very high risk (Group 4 patients receiving rituximab), high risk (group 3 patients receiving rituximab) and medium risk (Group3 or Group 4 patients receiving TNFi or T-cell blockers, IL12/23 pathway inhibitor). Screening results for hepatitis $\mathrm{C}$ virus (HCV) were also evaluated.

Results: Among 1229 patients (79.7\% female), mean age was $54.9 \pm 11.7$ and mean disease duration was $12.3 \pm 8.2$ years. In total, $104(22.2 \%)$ of patients had received rituximab. Serology for $\mathrm{HbsAg}$, anti-Hbs and anti-HbC were avaliable in 468 patients. There were $273(58.3 \%)$ patients in group 1, $81(17.3 \%)$ in group $2,19(4.1 \%)$ in group $3,9(1.9 \%)$ in group 4 and $86(18.3 \%)$ in group 5. Table 1 represents distribution of patients according to HBV reactivation risk. Anti-HCV was positive in $21(2.5 \%)$ of patients.

Table 1. Distribution of patients according to HBV reactivation risk

\begin{tabular}{lc}
\hline HBV reactivation risk $(\%)$ & $\mathrm{N}(\%)$ \\
\hline Very high risk $(>\% 20)$ & $2(\% 0.4)$ \\
High risk $(\% 11-20)$ & $22(\% 4.7)$ \\
Medium risk $(\% 1-10)$ & $81(\% 17.3)$ \\
No risk & $363(\% 77.6)$ \\
\hline
\end{tabular}

Conclusions: Among patients registered in HUR-BIO, 1.9\% had chronic HBV infection and $2.5 \%$ anti-HCV positivity. $5.0 \%$ of them were under high and/or very high risk for HBV reactivation. Medium risk group which includes $17.0 \%$ of patients, seems to deserve most of the attention. Screening for viral hepatitis must be performed before biologics and TSR guideline may be useful in this matter. References:

[1] Karadag O, Kasifoglu T et al. Guideline of the viral hepatitis screening before biologic agents use in patients with rheumatic diseases. RAED Journal;7:2832.

Disclosure of Interest: None declared

DOI: 10.1136/annrheumdis-2017-eular.4030

\section{AB0364 CHARACTERISTICS OF BLOOD PRESSURE PHEHOTYPES IN PATIENTS WITH RHEUMATOID ARTHRITIS - EULAR}

S. Velmakin, E. Troitskaya, S. Villevalde, Z. Kobalava. Propaedeutics of Internal Diseases, Rudn University, Moscow, Russian Federation

Background: Patients with rheumatoid arthritis (RA) have increased cardiovascular risk. Arterial hypertension $(\mathrm{AH})$ is highly prevalent, and seems to be under-diagnosed and under-treated among patients with RA. Data on ABPM profile in patients with rheumatoid arthritis are lacking.

Objectives: The aim of the study was to evaluate ABPM parameters and characterize phenotypes of blood pressure (BP) in patients with RA.

Methods: 62 patients with RA (EULAR 2010) without known cardio-vascular disease were examined (73\% females, age $58,5 \pm 15,4$ (M \pm SD) years, $13 \%$ smokers, $61 \%$ with $\mathrm{AH}, 34 \%$ with dyslipidemia). Median duration of RA was 8 years (IQR 3-17). Seropositive RA was diagnosed in $69 \%$ of patients. Median CRP was $12,1 \mathrm{mg} / \mathrm{dl}$ (IQR 2,2-23,4 mg/dl), median rheumatoid factor (RF) was 32,5 IU/ml (IQR 8,3-173 IU/ml). All patients received disease-modifying antirheumatic drugs (DMARDs), 22 (38\%) - biological treatment. Median duration of $\mathrm{AH}$ was 6,1 years (IQR $0-10$ years). All patients with AH received antihypertensive treatment. 24-h peripheral and central BP monitoring was performed (BPLab Vasotens, "Petr Telegin"). $\mathrm{P}<0.05$ was considered significant.

Results: Mean office BP was $130 \pm 15 / 80 \pm 10 \mathrm{mmHg}$ (peripheral) and $123 \pm 21 / 80 \pm 10 \mathrm{mmHg}$ (central). $10(17 \%)$ patients had elevated office BP $(>140 / 90 \mathrm{mmHg}$ ). Mean BP values for peripheral and central BP were as follows: $125 \pm 15 / 73 \pm 9$ and $116 \pm 14 / 75 \pm 9 \mathrm{mmHg}$ for $24-\mathrm{h} \mathrm{BP} ; 127 \pm 15 / 74 \pm 9$ and $117 \pm 14 / 77 \pm 9 \mathrm{mmHg}$ for daytime BP; $119 \pm 15 / 69 \pm 10$ and $112 \pm 15 / 70 \pm 10 \mathrm{mmHg}$ for nighttime BP. AH according to daytime BP was found in $15(24,2 \%)$ pts, nighttime BP - in $29(46,8 \%)$ pts, 24-h BP - in $19(30,6 \%)$ pts. Phenotypes of BP were as follows: sustained normotension - in $38(61,2 \%)$, masked hypertension in $12(19,4 \%)$, sustained $\mathrm{AH}$ - in $10(16,1 \%)$, white-coat hypertension in $2(3,2 \%)$ patients. Isolated nocturnal AH was observed in $12(19,4 \%)$ pts. $10(16,1 \%)$ patients had isolated elevated central BP. $20(32,3 \%)$ pts had elevated central SBP according to individual reference values; all patients with high office BP had elevated central BP.

Conclusions: Patients with RA free of CVD are characterized by high prevalence of with the satisfactory control of office BP in the majority of patients. Relatively high prevalence of masked and isolated nocturnal hypertension despite antihypertensive treatment is observed in this population. These findings may help to optimize hypertension treatment in patients with RA. 
References:

[1] Ambrosino P. et al. Subclinical Atherosclerosis in Patients With Rheumatoid Arthritis. A Meta-Analysis of Literature StudiesThromb Haemost 2015; 113: 916-930.

[2] Avina-Zubieta JA et al. Risk of cardiovascular mortality in patients with rheumatoid arthritis: a meta-analysis of observational studies. Arthritis Rheum 2008; 59:1690-7.

[3] Protogerou A.D., Panagiotakos D.B., Zampeli E. Arterial hypertension assessed "out-of-office" in a contemporary cohort of rheumatoid arthritis patients free of cardiovascular disease is characterized by high prevalence, low awareness, poor control and increased vascular damage-associated "white coat" phenomenon. Arthritis Res Ther. 2013;15(5):R142.

[4] Panoulas V.F., Metsios G.S., Pace A.V. Hypertension in rheumatoid arthritis. Rheumatology (Oxford). 2008;47(9):1286-98.

[5] Hamamoto K., Yamada S., Yasumoto M. Et al. Association of nocturnal hypertension with disease activity in rheumatoid arthritis. Am J Hypertens 2016;29(3):340-7

Disclosure of Interest: None declared

DOI: 10.1136/annrheumdis-2017-eular.5382

\section{AB0365 HENOCH-SCHÖNLEIN PURPURA IN TUNISIAN ADULTS: MONOCENTRIC STUDY}

S. Hammami, M. Nasr, N. Sassi, R. Klii, M. Kechida, I. Kochtali. Internal medicine, University Hospital F Bourguiba Monastir, Monastir, Tunisia

Background: Henoch-Schonlein purpura (HSP) is a non thrombopenic leucocytoclasic acute systemic vasculitis of the small vessels with IgA-immun complex deposits, most commonly affecting the skin, joints, gastro-intestinal tract and the kidneys. It commonly affects the children aged between 4 to 10 years. The occurrence of HSP in adults is significantly less frequent with atypical profile, and more serious complications.

Objectives: Analysis of the clinical presentations, biological characteristics, treatment and evolutions of HSP in this population, compared with other tunisian and international studies.

Methods: This is a monocentric retrospective study using an operating record data from 30 adult patients aged 16 to 82 years hospitalized for HSP in Internal Medicine Department in Monastir university hospital between May 2005 to July 2015. Inclusion criteria's where those defined in 2006 by the European League Against Rheumatism (ELAR) and the Pediatric Rheumatology European Society (PRES) for the diagnosis of HSP.

Results: Thirty patients with Henoch-Schönlein purpura (18 women and 12 men) were included in the study. The mean age at onset of the disease was $48.80 \pm 18.77$ years (16 -82 years). The vascular purpura was the most frequent inaugural clinical manifestation (90\%). It was diffuse and necrotic in 3.3\% of cases. Cutaneous biopsy practiced in 26 cases (86.6\%), found leukocytoclastic vasculitis in 21 cases $(80.7 \%)$. Joint involvement was present in $80 \%$ : Inflammatory arthralgia in $56.6 \%$ and arthritis in $23,3 \%$. Sixteen patients (53.3\%) had gastro-intestinal involvement: Gastric and duodenal ulcers, occlusive syndrome, gastrointestinal bleeding and pancreatitis in $26,6 \%, 16,6 \%, 10 \%$ and $3,3 \%$ respectively. Eighteen patients $(60 \%)$ had renal involvement. Nephritic syndrome was observed in thirteen patients $(43,33 \%)$. Hematuria was objectified in 11 patients. Four patients had renal failure $(13,33 \%)$. The renal biopsy practiced in 4 cases, objectified IgA nephropathy in 3 patients and glomerulonephritis extra-capillary in 1 case. Interstitial lung disease with bilateral pleurisy was observed in a patient. A woman had a cerebral vasculitis. Corticosteroids were prescribed in 8 patients for gastrointestinal and renal impairment. Two patients received cyclophosphamide cures for cerebral vasculitis and severe digestive impairment. Anti-inflammatory drugs were prescribed in 9 cases. A favorable spontaneous development was observed in 9 patients. A recurrence was reported in 2 cases. One patient dead by severe sepsis.

Conclusions: HSP manifests in adult patients as a more severe and atypical disease with more relapses and more frequent and severe gastro-intestinal and renal disease. HSP in adults requires a sustainable monitoring and more aggressive treatment

References:

[1] José M et al Henoch-SchöNlein Purpura in Adults; Clinics. 2008 Apr; 63(2): 273-276.

[2] Danhua Shu et al. Risk factors of progressive IgA nephropathy which progress to end stage renal disease within ten years: a case-control study, BMC Nephrol. 2017; 18: 11

Acknowledgements: Department of Immunology, university Hospital, F Bourguiba Monastir Tunisia.

Disclosure of Interest: None declared

DOI: 10.1136/annrheumdis-2017-eular.4479

\section{AB0366 "I JUST WANT MY LIFE BACK": PHYSICAL FUNCTION AND FATIGUE ARE CRITICAL TARGETS FOR IMPROVING PARTICIPATION AND HRQL IN RHEUMATOID ARTHRITIS}

S.J. Bartlett $^{1,1}$, A. Sirois ${ }^{2}$, N. Chiarlitti ${ }^{2}$, M. Inceer ${ }^{2}$, M. Jones ${ }^{3}$, C.O. Bingham ${ }^{3}$. ${ }^{1}$ Medicine; ${ }^{2}$ Mcgill University, Montreal, Canada; ${ }^{3}$ Johns Hopkins, Baltimore, USA

Background: The primary goal of treatment for rheumatoid arthritis (RA) is to maximize health-related quality of life (HRQL) through symptom and damage control, and normalize function and participation in social and life activities. Although fatigue is recognized as one of the most debilitating symptoms of RA, little is known about how fatigue impacts participation.

Objectives: We hypothesized that fatigue, along with pain, mood, disease activity, and disability would be associated with reduced participation.

Methods: RA patients enrolled in an observational study at an academic center completed PROMIS measures assessing fatigue, physical function, mood (depression and anxiety), pain interference, sleep disturbance, and participation. RA clinical indicators were also collected at the visit. Variance inflation factors were examined to evaluate collinearity among variables. Covariates/confounders independently associated with participation included pain, mood (depression, anxiety), sleep, disease activity (CDAl), and physical function. Multiple regression models that did and did not include pain were compared using likelihood ratio tests with SPSS and R.

Results: Participants were mostly female (82\%) and white (83\%) with mean (SD) age of 56 (13) years; $24 \%$ had $\leq$ high school, $29 \%$ had RA $\leq 5$ years with $13 \%$ $\leq 2$ years, and $22 \%$ were disabled. Mean CDAl was 7.9 (7.8). Most were in CDAI remission $(n=56 ; 32 \%)$ or LDA $(n=67 ; 38 \%) ; 39(22 \%)$ were in MDA and $14(8 \%)$ in HDA. Mean PROMIS fatigue was 53.9 (10.0); fatigue increased across CDAI levels from 46.2 (8.6) in remission to 64.0 (9.6). Only those with HDA had mean sleep, depression or anxiety scores $>55$ (i.e., above population norms).

In the full model, fatigue, depression, CDAI, and physical function were significant independent predictors of reduced participation in social roles and activities $(F(2$, $162)=29.75, p<.001$, adjusted $\left.r^{2}=.55\right)$. Contrary to our hypothesis, pain was not associated with participation in univariate or multivariate models.

Conclusions: Our results suggest that in RA patients, high levels or fatigue are common; conversely, depression, anxiety, and sleep disturbance were elevated only in people with HDA. Disability and fatigue appear to have the greatest impact on participation in social roles and activities. RA treatments and interventions that attenuate fatigue and improve mood in people with active RA may improve their ability to participate in social and life situations restoring a sense of normalcy and improving HRQL.

Acknowledgements: Funding: PCORI IP2-PI0000737 and SC14-1402-10818, CIHR 312205.

Disclosure of Interest: None declared

DOI: 10.1136/annrheumdis-2017-eular.5597

\section{AB0367 THE PROPHYLACTIC EFFECT OF SULFASALAZINE AGAINST PNEUMOCYSTIS PNEUMONIA: AN ANALYSIS OF INCIDENCE FOR PNEUMOCYSTIS PNEUMONIA IN PATIENTS WITH RHEUMATOID ARTHRITIS IN JAPAN}

T. Nunokawa, N. Yokogawa, K. Shimada, S. Sugii. Department of Rheumatic Diseases, Tokyo Metropolitan Tama Medical Center, Fuchu-shi, Japan

Background: Cases with Pneumocystis pneumonia (PCP) have been reported in patients with rheumatoid arthritis, mainly treated with biologics. An experimental study in the mouse revealed that sulfasalazine enhances the clearance of the Pneumocystis organism from the lung (1). Furthermore, a case-control study with small sample size indicated possible preventive effect of sulfasalazine against PCP (2).

Objectives: The aim of this study is to clarify the prophylactic effect of sulfasalazine against PCP in patients with rheumatoid arthritis with a large sample size.

Methods: This retrospective study focused on all patients with rheumatoid arthritis seen between April, 2011 and October, 2016. at department of rheumatology, Tokyo Metropolitan Tama Medical Center. We investigated their demographics and medication, including corticosteroids, disease-modifying antirheumatic drugs and prophylactic drugs against PCP. The person-time at risk was calculated from prescription records. We compared the incidence during the period of follow-up in which the patients received sulfasalazine with that in which they did not received sulfasalazine. The incidents were assumed to follow a Poisson distribution and statistical analysis was performed using z-test.

Results: In the study period, 2,394 patients with rheumatoid arthritis were treated at our hospital. Among them, 24 patients received the treatment for PCP because the infection was diagnosed or was strongly suspected. All the cases developed the condition while they were not taking sulfasalazine. The incidence rate of PCP was significantly lower in the treatment period with sulfasalazine than that without sulfasalazine $(p<0.001)$.

Conclusions: Our study confirmed that sulfasalazine has a preventive effect against PCP in patients with rheumatoid arthritis.

\section{References:}

[1] Wang J, Gigliotti F, Bhagwat SP, George TC, Wright TW. Immune modulation with sulfasalazine attenuates immunopathogenesis but enhances macrophage- mediated fungal clearance during pneumocystis pneumonia. PLoS Pathog. 2010;6(8):59-60.

[2] Mizushina K, Hirata A, Hayashi N, et al. Possible preventive effect of salazosulfapyridine against development of Pneumocystis pneumonia in methotrexate-receiving patients with rheumatoid arthritis. Mod Rheumatol. 2015;7595(November):1-8.

Disclosure of Interest: None declared

DOI: 10.1136/annrheumdis-2017-eular.6083 